University of Wollongong

Research Online

Faculty of Social Sciences - Papers (Archive) Faculty of Arts, Social Sciences \& Humanities

2013

Sequential processing in the equiprobable auditory Go/NoGo task: A temporal PCA study

Robert Barry

University of Wollongong, rbarry@uow.edu.au

Frances M. De Blasio

University of Wollongong, francesd@uow.edu.au

Follow this and additional works at: https://ro.uow.edu.au/sspapers

Part of the Education Commons, and the Social and Behavioral Sciences Commons

Research Online is the open access institutional repository for the University of Wollongong. For further information contact the UOW Library: research-pubs@uow.edu.au 


\title{
Sequential processing in the equiprobable auditory Go/NoGo task: A temporal PCA study
}

\author{
Abstract \\ The unwarned auditory equiprobable Go/NoGo task provides a convenient means to assess differential \\ processing, although our interpretations remain limited by the lack of research regarding the range of \\ elicited components and their functional significance. We examined sequential processing in this \\ paradigm, presenting 24 participants with a total of 300 trials in two blocks. EEG was recorded from 19 \\ channels, and the Go and NoGo event-related potentials were decomposed using temporal Principal \\ Components Analysis. Of the 218 unrestricted Varimax-rotated factors, seven were identifiable as \\ components based on their latency, polarity, and topography: early N1, Processing Negativity (PN), and P2 \\ components were followed by N2, P3, the classic Slow Wave (SW), and a diffuse Late Positivity (LP). N1 \\ was enhanced to Go, as was the defining temporal topography of PN. NoGo produced increased \\ centroparietal P2, frontocentral N2, and P3a, in comparison to Go, which produced a more parietal N2 and \\ $\mathrm{P} 3 \mathrm{~b}$, and an enhanced SW. The LP was larger in NoGo. These results suggest that N1 marks the \\ beginning of Go and NoGo differentiation. Complete Go/NoGo categorisation is marked by N2; this is \\ followed by different processing chains leading to the NoGo non-response (marked by P3a) and Go \\ response (marked by P3b and SW). The larger LP in NoGo marks the cortical inactivation following the \\ earlier cessation of processing in this condition.
}

\section{Keywords}

equiprobable, auditory, go, nogo, task, temporal, pca, study, sequential, processing

\section{Disciplines}

Education | Social and Behavioral Sciences

\section{Publication Details}

Barry, R. J. \& De Blasio, F. M. (2013). Sequential processing in the equiprobable auditory Go/NoGo task: A temporal PCA study. International Journal of Psychophysiology, 89 (1), 123-127. 
Sequential Processing in the Equiprobable Auditory Go/NoGo Task: A Temporal PCA Study

Robert J. Barry* and Frances M. De Blasio

Centre for Psychophysics, Psychophysiology, and Psychopharmacology, Brain \& Behaviour Research Institute, and School of Psychology, University of Wollongong, Wollongong 2522, Australia

*Corresponding author

Phone/fax: +61242214421

Email: robert_barry@uow.edu.au (R.J. Barry)

Address: School of Psychology, University of Wollongong, Wollongong NSW 2522, Australia. 


\section{Abstract}

The unwarned auditory equiprobable Go/NoGo task provides a convenient means to assess differential processing, although our interpretations remain limited by the lack of research regarding the range of elicited components and their functional significance. We examined sequential processing in this paradigm, presenting 24 participants with a total of 300 trials in two blocks. EEG was recorded from 19 channels, and the Go and NoGo event-related potentials were decomposed using temporal Principal Components Analysis. Of the 218 unrestricted Varimax-rotated factors, seven were identifiable as components based on their latency, polarity, and topography: early N1, Processing Negativity (PN), and P2 components were followed by N2, P3, the classic Slow Wave (SW), and a diffuse Late Positivity (LP). N1 was enhanced to Go, as was the defining temporal topography of PN. NoGo produced increased centroparietal P2, frontocentral N2, and P3a, in comparison to Go, which produced a more parietal N2 and P3b, and an enhanced SW. The LP was larger in NoGo. These results suggest that N1 marks the beginning of Go and NoGo differentiation. Complete Go/NoGo categorisation is marked by N2; this is followed by different processing chains leading to the NoGo non-response (marked by P3a) and Go response (marked by P3b and SW). The larger LP in NoGo marks the cortical inactivation following the earlier cessation of processing in this condition.

Keywords: ERPs; Equiprobable Go/NoGo paradigm; Principal Components Analysis (PCA) 


\section{Introduction}

The auditory equiprobable Go/NoGo task has received limited attention in the literature. We have found it useful in brain dynamics studies because it provides equal numbers of two different ERP profiles, representing different processing chains, allowing average ERPs to be obtained for each with maximal efficiency (e.g., Barry, 2009). In previous work we have used this paradigm to examine the impact on subsequent ERP components of prestimulus EEG phase (e.g., in children: Barry and De Blasio, 2012) and amplitude (e.g., in adults: De Blasio and Barry, 2013), but were hampered in understanding the functional nature of some of the effects by the absence of relevant literature. This led us to the current study, the first to employ Principal Components Analysis (PCA) to assess the range of components present in this paradigm. We aim to clarify the nature of the ERP components associated with this task, particularly in regard to the differential (Go vs. NoGo) processing involved. This will enable future studies to explore a range of questions (e.g., in relation to development and brain dynamics) with a better basic understanding of the brain processing involved in the equiprobable Go and NoGo paradigm.

The equiprobable Go/NoGo ERPs share features of the auditory oddball: sequential N1, P2, N2, and P3 components, followed by the posterior-positive/anterior-negative classic Slow Wave (SW). P3 to the Go/target is larger and more parietal than that to the NoGo/standard; we follow Barry and Rushby (2006) who argued for the identification of these sub-components in this paradigm as P3b and P3a, respectively. In general, the equiprobable Go/NoGo ERPs appear similar to reduced oddball target ERPs and enhanced oddball standard ERPs (Duncan-Johnson and Donchin, 1977; Johnson, 1986), respectively.

Here we expect to find a chain of broadly similar components to both Go and NoGo stimuli. N1 and P2 are early components largely reflecting sensory processing, and are not expected to differ between conditions (Barry, 2009). N2 subcomponents are rarely explored in the auditory Go/NoGo context, but an anterior control-related N2 is most likely to NoGo (Huster et al., 2013), with a more posterior negativity to Go (Folstein and van Petten, 2008). We predicted an anterior P3a to NoGo, 
and a posterior P3b to Go (Barry and Rushby, 2006). The classic SW is seldom explored nowadays, but the posterior positivity and frontal negativity defining the SW may represent separable subcomponents (Loveless et al., 1987; Spencer et al., 2001; but see Dien, 2012). Evidence for these components requires decomposition of the Go/NoGo ERPs; this is attempted here using temporal PCA.

\section{Methods}

\subsection{Participants}

Twenty four predominantly right-handed (22/24) undergraduate students (14 females), aged $17-46(M=21.3)$ years, were screened for neurological disorders, head injury, learning disability and psychiatric conditions, and abstained from caffeine/psychoactive substances for $4 \mathrm{~h}$ prior to testing. Informed consent was obtained as approved by the local Ethics Committee.

\subsection{Physiological recording}

EEG was recorded from 19 scalp sites $(\times 20,000$ gain), using an electrode cap referenced to linked ears; care was taken to balance ear impedances (below $5 \mathrm{~K} \Omega$ ). Vertical and horizontal electro-oculograms (EOGs) were also recorded ( $\times 5,000$ gain). Data from 0.03 to $35 \mathrm{~Hz}$ were sampled by a 16 bit A/D system (AMLAB II) at $512 \mathrm{~Hz}$.

\subsection{Task and procedure}

An unwarned auditory Go/NoGo task was used. Participants received two blocks of 150 tones (50 ms duration, $5 \mathrm{~ms}$ rise/fall times), binaurally via headphones at $60 \mathrm{~dB}$ SPL, with a fixed stimulus onset asynchrony of $1,100 \mathrm{~ms}$. Half the tones were $1000 \mathrm{~Hz}$, and half $1500 \mathrm{~Hz}$, and these were presented in random order. Participants had to press a button with their dominant hand in response to one of the tones; this 'target' frequency alternated between subjects.

\subsection{ERP quantification and analysis}

Waveforms were low-pass filtered (0 to $25 \mathrm{~Hz}$; Fast Fourier Transform option) within EEGLAB (Version 6.01b; Delorme and Makeig, 2004) and then epoched offline using Neuroscan 
software (Compumedics, Version 4.3). Single trials containing muscular or other artefact, or incorrect responses (NoGo commissions; Go omissions or RTs $>500 \mathrm{~ms}$ ) were excluded. ERPs were derived from -100 to $+750 \mathrm{~ms}$ relative to stimulus onset, and baselined relative to the prestimulus period.

Pre- and post-stimulus data (-100 ms to $+750 \mathrm{~ms}: 436$ data points) from 19 scalp locations were submitted to a temporal PCA using Dien's ERP PCA toolkit (v. 2.23; Dien, 2010) in MATLAB $®$ (The Mathworks, R14SP3); input was 48 data files (912 cases: 24 participants $\times 2$ conditions $\times 19$ sites). Data for the PCA were half sampled to 218 time-points (variables) to reduce computation time and increase the ratio of cases/components (resulting in a ratio of $\sim 4: 1$; see Gorsuch, 1983). The PCA used the covariance matrix with Kaiser normalization, and all 218 unrestricted factors were subject to Varimax rotation following Kayser and Tenke (2003). PCA factors were identified as ERP components based on their latency, polarity, and topographic distribution.

A repeated-measures MANOVA examined the effects of Condition (Go vs. NoGo) for each of the identified components, assessing the virtual ERP amplitudes at 9 central sites (F3, Fz, F4, C3, $\mathrm{Cz}, \mathrm{C} 4, \mathrm{P} 3, \mathrm{Pz}, \mathrm{P} 4)$. Each analysis included examination of topography, with sagittal plane [frontal (F3, Fz, F4), central (C3, Cz, C4) and parietal (P3, Pz, P4)] and coronal plane [left (F3, C3, P3), midline $(\mathrm{Fz}, \mathrm{Cz}, \mathrm{Pz})$ and right $(\mathrm{F} 4, \mathrm{C} 4, \mathrm{P} 4)]$ as repeated-measures factors. Planned contrasts within the sagittal plane compared frontal vs. parietal regions, and central sites vs. the mean of the frontal and parietal sites. Within the coronal plane, the left vs. right regions, and the midline vs. the mean of the left and right sites, were analysed. These orthogonal planned contrasts provide optimal information on the topographic distribution of the amplitude of each component. Since all contrasts were planned and there were no more of them than the degrees of freedom for effect, no Bonferronitype adjustment to $\alpha$ was necessary (Tabachnick and Fidell, 1989). Also, Greenhouse-Geisser type correction was not necessary because single degree of freedom contrasts are not affected by the violations of sphericity assumptions common in repeated-measures analyses of physiological data 
(O'Brien and Kaiser, 1985). All $F$ tests reported have $(1,23)$ degrees of freedom.

\section{Results}

\subsection{Grand mean ERPs}

There were few Go omission $(M=7.2 \%)$ or NoGo commission $(M=1.3 \%)$ errors. $\mathrm{N}$ for accepted trials was $65-145(M=109.5, S D=18.2)$ for $G$, and $79-137(M=113.2, S D=16.1)$ for NoGo. Mean Go RT was $303.3(S D=47.1) \mathrm{ms}$. Midline grand mean ERPs are shown in the top row of Figure 1 panel $\mathrm{A}$, and the expected components are indicated (in Fz plot). A marked frontocentral N1 ( 100 ms) is apparent with a prominent P3 $(\sim 300 \mathrm{~ms})$; Go P3 is posterior, and NoGo P3 frontocentral. P2 and N2 peaks are apparent as inflection points between the major peaks; these are relatively small in relation to the dominant components. P3 appears to be followed by a classic frontal-negative/posterior-positive SW around $420 \mathrm{~ms}$, with a subsequent Late Positivity (LP) that appears more positive for NoGo.

Figure 1 about here

\subsection{PCA outcomes}

Of the 218 extracted temporal factors, the first seven explained $90.7 \%$ of the variance. The sums of these virtual temporal components at the midline sites are displayed in Figure 1 panel A (middle row); comparison with the raw ERPs (top row) confirms good fit with the original data. The Go-NoGo difference waveforms are also shown in Figure 1 panel A (bottom row), and again little variation is seen between the mean and virtual ERPs.

In Figure 1 panel $\mathbf{B}$, the topographic headmaps of the virtual temporal components are displayed averaged across condition, and these are presented above the loadings of the factors displayed against time. These loadings represent the unscaled correlations between the component and the ERP waveform (Tabachnick and Fidell, 1989). The percentage of the total variance accounted for by each rotated component is also indicated. The dominant components (factors 1-7, contributing to the virtual ERPs; Figure 1 panel A) were tentatively identified in terms of sequence 
and latency as N1, Processing Negativity (PN), P2, N2, P3, the classic SW, and LP. This N1 is probably the dominant frontocentral "real" Component 1 of the N1 identified by Näätänen and Picton (1987), and the PN fits with Näätänen and Picton's (1987) description of a later negativity in the broad N1 time range that "lasts during the processing of an attended auditory stimulus" (P. 412). Two additional identifiable components are included in Figure 1 panel B, tentatively labelled as P1 (at $52.7 \mathrm{~ms}$ ) and N1-3 (at $76.2 \mathrm{~ms}$ ), a second "real" N1 component (N1 Component 3: Näätänen and Picton, 1987) identifiable by its vertex topography and early latency. These two components (factors 9-10) followed, in factor order, a small unidentifiable frontal negativity at $561 \mathrm{~ms}$; they contributed < $1 \%$ each to the variance, and were not assessed further. The separate Go and NoGo topographic headmaps of the assessed virtual temporal components are displayed in Figure 1 panel C.

\subsection{PCA component amplitudes}

Over conditions, N1 was frontocentral $\left(\mathrm{F}>\mathrm{P}: F=18.93, p<.001, \eta_{p}{ }^{2}=.45 ; \mathrm{C}>\mathrm{F} / \mathrm{P}: F=\right.$ $\left.35.26, p<.001, \eta_{p}^{2}=.61\right)$, with a frontal-right and vertex enhancement $(\mathrm{F}>\mathrm{P} \times \mathrm{L}<\mathrm{R}: F=6.74, p=$ $\left..016, \eta_{p}{ }^{2}=.23 ; \mathrm{C}>\mathrm{F} / \mathrm{P} \times \mathrm{M}>\mathrm{L} / \mathrm{R}: F=5.26, p=.031, \eta_{p}{ }^{2}=.19\right)$ and a frontal-midline reduction $(\mathrm{F}$ $>\mathrm{P} \times \mathrm{M}<\mathrm{L} / \mathrm{R}: F=6.12, p=.021, \eta_{p}{ }^{2}=.21$ ); see Figure 1 panel $\mathrm{B} . \mathrm{N} 1$ to Go was enhanced in the midline $\left(\mathrm{Go}>\mathrm{NoGo} \times \mathrm{M}>\mathrm{L} / \mathrm{R}: F=8.65, p=.007, \eta_{p}{ }^{2}=.27\right)$, contributing to a main effect of condition (Go > NoGo: $F=5.41, p=.029, \eta_{p}^{2}=.19$ ); compare Go vs. NoGo N1 headmaps, Figure 1 panel C.

Across Go and NoGo, the central negativity of the PN appeared to increase with distance from the vertex, but it was uniformly distributed over the nine core scalp sites initially analysed; this can be seen in Figure 1, panel B. Although there was no main effect of condition, NoGo PN was larger centrally (Go $<$ NoGo $\left.\times \mathrm{C}>\mathrm{F} / \mathrm{P}: F=5.54, p=.027, \eta_{p}{ }^{2}=.19\right)$. A supplementary analysis including the outer electrode rows (replacing the F3/4, C3/4, P3/4 electrode pairs by F7/8, T3/4, T5/6) found a central distribution $\left(\mathrm{C}>\mathrm{F} / \mathrm{P}: F=34.43, p<.001, \eta_{p}{ }^{2}=.60\right)$, and elevations in the hemispheres $\left(\mathrm{M}<\mathrm{L} / \mathrm{R}: F=5.48, p=.020, \eta_{p}{ }^{2}=.19\right)$, particularly centrally $(\mathrm{C}>\mathrm{F} / \mathrm{P} \times \mathrm{M}<\mathrm{L} / \mathrm{R}: F=$ 
$\left.13.76, p=.001, \eta_{p}{ }^{2}=.37\right)$. This temporal enhancement was larger for Go $\mathrm{PN}(\mathrm{Go}>\mathrm{NoGo} \times \mathrm{C}>\mathrm{F} / \mathrm{P}$ $\times \mathrm{M}<\mathrm{L} / \mathrm{R}: F=8.04, p=.009, \eta_{p}{ }^{2}=.26$ ); see Figure 1 panel C. Together these analyses indicate that the temporal PN was greater for Go than NoGo.

As seen in Figure 1 panel B, P2 was centroparietal across conditions $(\mathrm{F}<\mathrm{P}: F=6.27, p=$ $\left..020, \eta_{p}{ }^{2}=.21 ; \mathrm{C}>\mathrm{F} / \mathrm{P}: F=25.95, p<.001, \eta_{p}{ }^{2}=.53\right)$, with a midline dominance $(\mathrm{M}>\mathrm{L} / \mathrm{R}: F=$ $\left.20.91, p<.001, \eta_{p}{ }^{2}=.48\right)$, and vertex maximum $\left(\mathrm{C}>\mathrm{F} / \mathrm{P} \times \mathrm{M}>\mathrm{L} / \mathrm{R}: F=7.32, p=.013, \eta_{p}{ }^{2}=.24\right)$. NoGo P2 was enhanced centroparietally (Go $<$ NoGo $\times \mathrm{F}<\mathrm{P}: F=9.20, p=.006, \eta_{p}{ }^{2}=.29$; Go $<$ NoGo $\times \mathrm{C}>$ F/P: $\left.F=5.70, p=.026, \eta_{p}{ }^{2}=.20\right)$, and in the left hemisphere $(\mathrm{Go}<$ NoGo $\times \mathrm{L}>\mathrm{R}: F=$ $\left.10.43, p=.004, \eta_{p}^{2}=.31\right)$; this is clearly evident in Figure 1 panel $\mathrm{C}$.

Across conditions, N2 was frontal $\left(\mathrm{F}>\mathrm{P}: F=4.56, p=.044, \eta_{p}{ }^{2}=.17 ; \mathrm{C}<\mathrm{F} / \mathrm{P}: F=4.42, p=\right.$ $\left..047, \eta_{p}{ }^{2}=.16\right)$, and reduced in the midline $\left(\mathrm{M}<\mathrm{L} / \mathrm{R}: F=24.76, p<.001, \eta_{p}{ }^{2}=.52\right)$, particularly frontally $\left(\mathrm{F}>\mathrm{P} \times \mathrm{M}<\mathrm{L} / \mathrm{R}: F=4.37, p=.048, \eta_{p}{ }^{2}=.16\right)$; the central reduction was larger on the left $\left(\mathrm{C}<\mathrm{F} / \mathrm{P} \times \mathrm{L}>\mathrm{R}: F=5.45, p=.029, \eta_{p}{ }^{2}=.19\right)$ and largest at the midline $(\mathrm{C}<\mathrm{F} / \mathrm{P} \times \mathrm{M}>\mathrm{L} / \mathrm{R}: F=$ 20.57, $p<.001, \eta_{p}{ }^{2}=.47$ ). As evident in Figure 1 panel C, N2 for Go was greater (i.e., more negative) in the midline (Go $>$ NoGo $\times \mathrm{M}>\mathrm{L} / \mathrm{R}: F=11.70, p=.002, \eta_{p}{ }^{2}=.34$ ), particularly at the $\operatorname{vertex}\left(\mathrm{Go}>\mathrm{NoGo} \times \mathrm{C}>\mathrm{F} / \mathrm{P} \times \mathrm{M}>\mathrm{L} / \mathrm{R}: F=6.65, p=.017, \eta_{p}{ }^{2}=.22\right)$.

As apparent in Figure 1 panel B, P3 over conditions was centroparietal $(\mathrm{F}<\mathrm{P}: F=21.35, p<$ $\left..001, \eta_{p}{ }^{2}=.48 ; \mathrm{C}>\mathrm{F} / \mathrm{P}: F=22.01, p<.001, \eta_{p}{ }^{2}=.49\right)$, and midline dominant $(\mathrm{M}>\mathrm{L} / \mathrm{R}: F=23.22$, $\left.p<.001, \eta_{p}{ }^{2}=.50\right)$. P3 was parietal for Go and central for NoGo $(\mathrm{Go}>\mathrm{NoGo} \times \mathrm{F}<\mathrm{P}: F=34.38, p$ $\left.<.001, \eta_{p}{ }^{2}=.60 ; \mathrm{Go}<\mathrm{NoGo} \times \mathrm{C}>\mathrm{F} / \mathrm{P}: F=6.20, p=.020, \eta_{p}{ }^{2}=.21\right)$; this can be seen in Figure 1 panel C. The parietal dominance of Go P3 was enhanced in the left hemisphere (Go $>$ NoGo $\times \mathrm{F}<\mathrm{P}$ $\left.\times \mathrm{L}>\mathrm{R}: F=6.79, p=.016, \eta_{p}{ }^{2}=.23\right)$. The NoGo P3 central enhancement was larger on the right and largest in the midline (Go $<$ NoGo $\times \mathrm{C}>\mathrm{F} / \mathrm{P} \times \mathrm{L}<\mathrm{R}: F=9.17, p=.006, \eta_{p}{ }^{2}=.28$; Go $<$ NoGo $\left.\times \mathrm{C}>\mathrm{F} / \mathrm{P} \times \mathrm{M}>\mathrm{L} / \mathrm{R}: F=6.34, p=.019, \eta_{p}^{2}=.22\right)$.

Across conditions, the $\mathrm{SW}$ was centroparietally positive and frontally negative (F $<\mathrm{P}: F=$ 
24.39, $p<.001, \eta_{p}{ }^{2}=.51 ; \mathrm{C}>\mathrm{F} / \mathrm{P}: F=21.97, p<.001, \eta_{p}{ }^{2}=.49$ ); see Figure 1 panel B. SW was more negative in the midline $\left(\mathrm{M}<\mathrm{L} / \mathrm{R}: F=9.40, p=.005, \eta_{p}{ }^{2}=.29\right)$. Also in the midline, the frontal negativity/parietal positivity was enhanced, and the central positivity was reduced $(\mathrm{F}<\mathrm{P} \times \mathrm{M}$ $\left.>\mathrm{L} / \mathrm{R}: F=8.09, p=.009, \eta_{p}{ }^{2}=.26 ; \mathrm{C}>\mathrm{F} / \mathrm{P} \times \mathrm{M}<\mathrm{L} / \mathrm{R}: F=4.54, p=.044, \eta_{p}{ }^{2}=.16\right)$. As evident in Figure 1 panel $\mathrm{C}$, the Go SW was enhanced centrally (Go $>$ NoGo $\times \mathrm{C}>\mathrm{F} / \mathrm{P}: F=17.85, p<.001$, $\eta_{p}{ }^{2}=.44$ ), and in the left centroparietal regions (Go $>$ NoGo $\times \mathrm{F}<\mathrm{P} \times \mathrm{L}>\mathrm{R}: F=5.07, p=.034, \eta_{p}{ }^{2}$ $=.18 ; \mathrm{Go}>\mathrm{NoGo} \times \mathrm{C}>\mathrm{F} / \mathrm{P} \times \mathrm{L}>\mathrm{R}: F=4.85, p=.038, \eta_{p}{ }^{2}=.17$ ). Overall, the $\mathrm{SW}$ was greater for Go than NoGo (Go > NoGo: $F=8.32, p=.008, \eta_{p}{ }^{2}=.27$ ).

The LP was globally positive with a central dominance $\left(\mathrm{C}>\mathrm{F} / \mathrm{P}: F=11.65, p=.002, \eta_{p}{ }^{2}=\right.$ 34) that was larger in the right hemisphere ( $\left.\mathrm{C}>\mathrm{F} / \mathrm{P} \times \mathrm{L}<\mathrm{R}: F=19.09, p<.001, \eta_{p}{ }^{2}=.45\right)$; see Figure 1 panel B. As clearly apparent in Figure 1 panel C, the Go LP was relatively smaller in the left hemisphere (Go $<$ NoGo $\left.\times \mathrm{L}>\mathrm{R}: F=14.92, p=.001, \eta_{p}{ }^{2}=.39\right)$ and in the frontal midline (Go $<$ NoGo $\times \mathrm{F}>\mathrm{P} \times \mathrm{M}>\mathrm{L} / \mathrm{R}: F=7.79, p=.010, \eta_{p}{ }^{2}=.25$ ). Overall, the LP was smaller for Go than NoGo (Go $<$ NoGo: $\left.F=9.49, p=.005, \eta_{p}{ }^{2}=.29\right)$.

\section{Discussion}

N1 and P3 were obvious as peaks in the raw ERPs in this equiprobable auditory Go/NoGo task, with some suggestion of a late classic SW (see Figure 1 panel A). As expected, the temporal PCA confirmed additional components (identifiable as the PN, P2, and N2), as well as a novel LP, and supported the frontal-negativity/posterior-positivity of the classic SW. Suggestions of an early P1 and Component 3 of the N1 were also noted; these are beyond the present paper, but should be pursued in future investigations. It is readily apparent that our understanding of the processing stages involved in this paradigm can only be advantaged by the identification and clarification of such additional markers of brain activity occurring before, between, and after the obvious N1 and P3 peaks. We first discuss the characteristics and identification of these components in temporal order, and then address their relation to Go vs. NoGo processing. 
N1 was frontocentral with some vertex enhancement, and a peak latency of $107.4 \mathrm{~ms}$, both compatible with expectations from Näätänen and Picton (1987), and our previous identification of such a component in a long-ISI auditory habituation task (Barry et al., 2011). PN, with a peak latency of $146.5 \mathrm{~ms}$, was generally diffuse but appeared to show a central negativity increasing with distance from the midline, compatible with generators in the "lateral aspects of the temporal lobe" (P. 412) as described by Näätänen and Picton (1987). This was confirmed in a supplementary analysis including the temporal electrodes. P2 had a latency of $205.1 \mathrm{~ms}$, and a centroparietal distribution with a vertex maximum, both compatible with expectations from Beauducel et al. (2000) and Crowley and Colrain (2004). The frontal N2 at $252.0 \mathrm{~ms}$ is broadly compatible with both mean amplitude and PCA-derived auditory N2s (e.g., Kaiser et al., 2006; Kayser et al., 2010). As is common in the auditory literature, P3 was centroparietal and midline dominant, and here had a peak latency of $314 \mathrm{~ms}$. Peaking at $431.6 \mathrm{~ms}$, the frontally negative and centroparietally positive SW matched well with the latency and topography of a PCA-derived SW previously reported by Barry et al. (2011) from a passive auditory habituation task in which no stimulus-related response was required. Interestingly, the subsequent globally-positive LP, with a peak latency of $654 \mathrm{~ms}$ and central and right-hemisphere dominance, is novel. It is possible that this component is merely $\mathrm{n}$ outcome of the autocorrelation of EEG time series at the end of the baselined ERP epoch (Kayser and Tenke, 2003). However, the waveforms in Figure 1 suggest a realistic component peak, and a follow-up extension of the ERP epoch indicated resolution of the Go/NoGo difference around 850 ms and substantial resolution of both responses by $1,000 \mathrm{~ms}$. Further discussion of this issue is beyond the present study, but it should be investigated further in future work.

N1 was larger in the midline to Go than to NoGo, contributing to an overall increased response to Go; this is apparent in the raw ERP peak, and the Go-NoGo difference wave, in Figure 1 panel A. In contrast, $\mathrm{PN}$ was larger to NoGo than to Go centrally, but its defining negativity in lateral temporal regions was enhanced to Go stimuli. The following P2 to NoGo was larger than the Go component in centroparietal and left hemisphere regions. There is little mention in the literature 
of Go/NoGo effects on the N1 or P2 (and none on PN), but Falkenstein et al. (1995) examined N1 and $\mathrm{P} 2$ peaks in an equiprobable auditory Go/NoGo task using words, and failed to find any task effects. In our previous peak studies in this paradigm, mixed results have been found. We have reported frontal enhancement in NoGo N1 and a parietal midline enhancement with a right bias in Go P2 (Barry et al., 2007), somewhat inconsistent with the present results; but have subsequently found frontal Go N1, and central-left NoGo P2, enhancements (De Blasio and Barry, 2013). The NoGo P2 enhancement is compatible with the suggestion that P2 marks the withdrawal of attention (Crowley and Colrain, 2004). Our findings here of clear task differences in N1, PN and P2 may reflect the greater resolution of the PCA component extraction compared with broader composite peak measures. For example, the separation of PN may contribute to this improved resolution, in that if the N1 and PN components were merged in a single traditional N1 peak, the central PN enhancement to NoGo would tend to counter the N1 enhancement to Go. Similarly, if the PN and P2 components were merged, the central NoGo enhancement of the PN might counter the centroparietal NoGo enhancement in P2.

The Go N2 was larger than the NoGo response in the midline and vertex; in the context of the overall dominant frontal N2, this marks a posterior Go shift. This finding is broadly compatible with current views of the anterior control-related N2 (Huster et al., 2013) and the more-posteriorly negative Go N2 (Folstein and van Petten, 2008), and thus supports the conflict-monitoring perspective of the N2. P3 showed the expected substantial separation into a parietal Go response and a central NoGo response (Barry and Rushby, 2006). The Go P3 had a left hemisphere bias and the NoGo P3, a right hemisphere bias, suggesting contralateral motoric central nervous system involvement/withdrawal (respectively) in the response/no response conditions of our largely-righthanded participants. This appears to contradict the findings of a right-hemisphere source for righthand responding (Tenke et al., 1998), and suggests the value of further exploration of the equiprobable paradigm. The Go SW showed enhanced centroparietal positivity (again with a left hemisphere bias), and was overall larger than SW to NoGo. In contrast, the novel LP was larger in 
the right hemisphere and parietal midline, and larger overall, for NoGo than Go.

The present data suggest the following processing milestones in the auditory equiprobable Go/NoGo task. As the PCA components are separated in the time dimension, this is necessarily a serial processing perspective. However, each of these components may reflect the scalp electrical outcomes of a vast complex of parallel neuronal processing, and this should not be ignored. At stimulus onset, initial stimulus transient processing is reflected in the $\mathrm{N} 1$, and further sensory processing is reflected in the $\mathrm{PN}$ and $\mathrm{P} 2$. Go responses are larger than NoGo in $\mathrm{N} 1$ and topographically so in $\mathrm{PN}$, indicating that identification of the stimulus characteristics defining Go/NoGo has begun. This is confirmed by the larger NoGo P2. Subsequent processing to complete categorisation of the stimulus is reflected in the N2. If the outcome of categorisation is "NoGo", basic processing continues, resulting in the maximal frontal N2 and a frontocentral NoGo P3, identified by Barry and Rushby (2006) as the P3a, followed by an enhanced LP. If the stimulus is categorised as "Go", there is a surge in directed, effortful processing, response preparation and execution: posterior N2 activity and a maximal posterior Go P3, identified by Barry and Rushby (2006) as the P3b, and large frontally negative/centroparietally positive Go SW follow. When taken together, the latter finding suggests a Go P3b-SW link. The subsequent novel LP, showing a NoGo enhancement, exhibited a relatively uniform distribution over the scalp. It seems reasonable to suggest that such a diffuse positivity indicates a broad cortical deactivation marking the end of stimulus processing; it is more substantive to NoGo than Go because of the earlier cessation of active processing of the NoGo stimulus. This novel component, and our interpretation of it, requires further investigation.

These results require replication, and the PCA approach used here could be further explored. We employed Varimax rotation to maintain orthogonality of the components, simplifying their conceptualisation. This has been a point of contention in the literature, with some advocating the alternative use of oblique rotations (e.g., Dien, 2012). Oblique rotations allow the components to be correlated, and narrow the component loading plots against time without substantial changes to the 
component peak latencies. We cannot address this dispute further here, but it would be interesting to compare the present orthogonal results with those obtained using oblique rotations.

Paradigm manipulations are also of interest in relation to the equiprobable version of the Go/NoGo explored here. For example, the generality of the present results could be explored with a shift from the equiprobable Go/NoGo towards the low probability Go usage common in traditional oddballs, or conversely, towards the low probability NoGo used in traditional Go/NoGo paradigms. Extension studies, with minor paradigm changes designed to explore aspects of the hypothetical processing chain proposed here, would also be useful. For example, separate PCAs of ERPs averaged from small trial blocks would allow evaluation of the component latencies at the individual level, supporting exploration of their linkage with behavioural parameters such as reaction time. The use of temporal PCA in this wider context should prove productive, and broaden our understanding of brain activity in this simple two-stimulus paradigm. 


\section{References}

Barry, R.J., 2009. Evoked activity and EEG phase resetting in the genesis of auditory Go/NoGo ERPs. Biol. Psychol. 80, 292-299.

Barry, R.J., Clarke, A.R., Johnstone, S.J., Magee, C.A., Rushby, J.A., 2007. EEG differences between eyes-closed and eyes-open resting conditions. Clin. Neurophysiol. 118, 2765-2773.

Barry, R.J., De Blasio, F.M., 2012. EEG-ERP phase dynamics of children in the auditory Go/NoGo task. Int. J. Psychophysiol. 86, 251-261.

Barry, R.J., MacDonald, B., Rushby, J.A., 2011. Single-trial event-related potentials and the orienting reflex to monaural tones. Int. J. Psyhophysiol. 79, 127-136.

Barry, R.J., Rushby, J.A., 2006. An orienting reflex perspective on anteriorisation of the P3 of the event-related potential. Exp. Brain Res. 173, 539-545.

Beauducel, A., Debener, S., Brocke, B., Kayser, J., 2000. On the reliability of augmenting/reducing: Peak amplitudes and principal component analysis of auditory evoked potentials. J. Psychophysiol. 14, 226-240.

Crowley, K.E., Colrain, I.M., 2004. A review of the evidence for P2 being an independent component process: Age, sleep and modality. Clin. Neurophysiol. 115, 732-744.

De Blasio, F.M., Barry, R.J., 2013. Prestimulus delta and theta determinants of ERP responses in the Go/NoGo task. Int. J. Psychophysiol. 87, 279-288.

Delorme, A., Makeig, S., 2004. EEGLAB: An open source toolbox for analysis of single-trial EEG dynamics including independent component analysis. J. Neurosci. Methods 134, 9-21.

Dien, J., 2010. The ERP PCA Toolkit: An open source program for advanced statistical analysis of event-related potential data. J. Neurosci. Methods 187, 138-145.

Dien, J., 2012. Applying Principal Components Analysis to event-related potentials: A tutorial. Dev. Neuropsychol. 37, 497-517.

Duncan-Johnson, C.C., Donchin, E., 1977. On quantifying surprise: The variation of event-related potentials with subjective probability. Psychophysiology 14, 456-467. 
Falkenstein, M., Koshlykova, N.A., Kiroj, V.N., Hoormann, J., Hohnsbein, J., 1995. Late ERP components in visual and auditory Go/Nogo tasks. Electroencephalogr. Clin. Neurophysiol. $96,36-43$.

Folstein, J.R., van Petten, C., 2008. Influence of cognitive control and mismatch on the N2 component of the ERP: A review. Psychophysiology 45, 152-170.

Gorsuch, R.L., 1983. Factor Analysis, $2^{\text {nd }}$ edn., Lawrence Erlbaum, NJ.

Huster, R.J., Enriquez-Geppert, S., Lavallee, C.F., Falkenstein, M., Herrmann, C.S., 2013. Electroencephalography of response inhibition tasks: Functional networks and cognitive contributions. Int. J. Psychophysiol. 87, 217-233.

Johnson, R., Jr., 1986. A triarchic model of P300 amplitude. Psychophysiology 23, 367-384.

Kaiser, S., Weiss, O., Hill, H., Markela-Lerenc, J., Kiefer, M., Weisbrod, M., 2006. N2 event-related potential correlates of response inhibition in an auditory Go/Nogo task. Int. J. Psychophysiol. $61,279-282$.

Kayser, J., Tenke, C.E., 2003. Optimizing PCA methodology for ERP component identification and measurement: Theoretical rationale and empirical evaluation. Clin. Neurophysiol. 114, 23072325.

Kayser, J., Tenke, C.E., Gil, R., Bruder, G.E., 2010. ERP generator patterns in schizophrenia during tonal and phonetic oddball tasks: Effects of response hand and silent count. Clin. EEG Neurosci. 41, 184-195.

Loveless, N.E., Simpson, M., Näätänen, R., 1987. Frontal negative and parietal positive components of the slow wave dissociated. Psychophysiology 24, 340-345.

Näätänen, R., Picton, T., 1987. The N1 wave of the human electric and magnetic response to sound: A review and an analysis of the component structure. Psychophysiology 24, 375-425.

O’Brien, R.G., Kaiser, M.K., 1985. MANOVA method for analyzing repeated measures designs: An extensive primer. Psychol. Bull. 97, 316-333. 
Spencer, K.M., Dien, J., Donchin, E., 2001. Spatiotemporal analysis of the late ERP responses to deviant stimuli. Psychophysiology 38, 343-358.

Tabachnick, B.G., Fidell, L.S., 1989. Using Multivariate Statistics, 2nd edn., Harper Collins, N.Y, $746 \mathrm{pp}$.

Tenke, C.E., Kayser, J., Fong, R., Leite, P., Towey, J.P., Bruder, G.E., 1998. Response- and stimulus-related ERP asymmetries in a tonal oddball task: A laplacian analysis. Brain Topogr. 10, 201-209. 


\section{Figure caption}

Figure 1. Panel A: Mean (top row) and corresponding virtual (middle row) Go and NoGo ERPs at the midline sites, and the Go-NoGo difference waveforms (bottom row). Panel B: Topographic headmaps and factor information for the identified virtual temporal components, with PCA loadings below. Panel C: Go and NoGo headmaps of the assessed temporal components. 
Figure 1
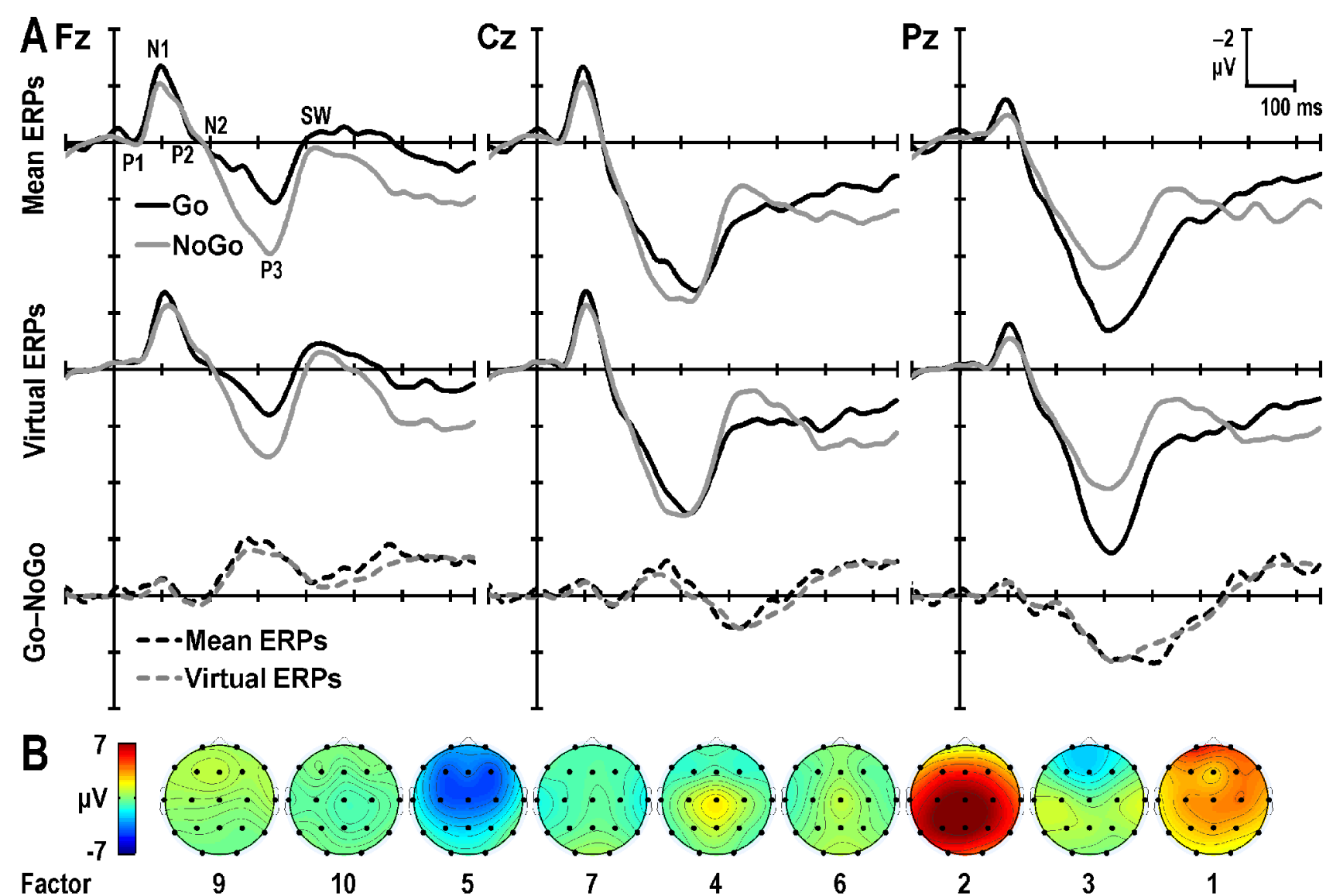

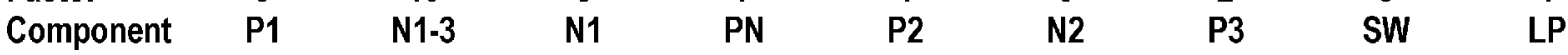
$\begin{array}{lllllllllll}\text { Variance } & 0.8 & 0.8 & 4.0 & 1.8 & 11.9 & 2.1 & 26.3 & 18.1 & 26.5 & \%\end{array}$

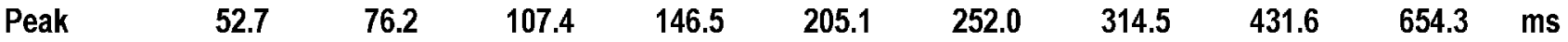
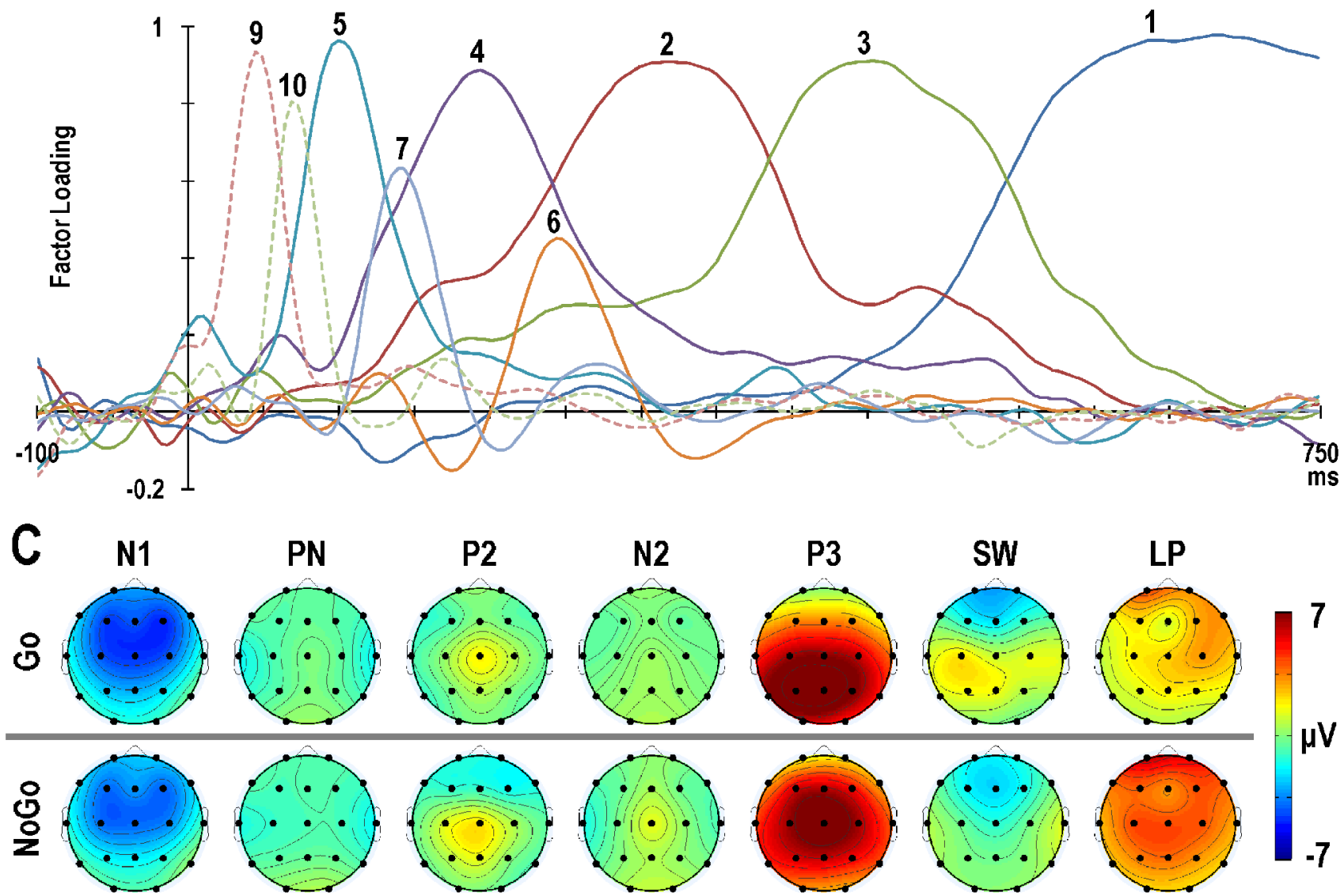